\title{
MANAGING REALITY SHOCK: EXPECTATIONS VERSUS EXPERIENCES OF GRADUATE ENGINEERS
}

\author{
SARAH RIORDAN \\ riordan@telkomsa.co.za \\ SUKI GOODMAN \\ Section of Organisational Psychology \\ School of Management Studies \\ University of Cape Town
}

\begin{abstract}
The objective of the study is an analysis of the relationship between the work expectations and experiences of graduate engineers during their early career period. It reports on discrepancies in graduates' expectations of the world of work and the reality of the early career stage. Conclusions include recommendations of how "reality shock" can be managed better by both organisations and individuals. Qualitative data were obtained through in-depth interviews with sixteen participants with less than five years work experience, employed in a large utility organisation in the Western Cape. Results indicate that participants experience significant incongruence between their expectations of work and work experiences.
\end{abstract}

Key words

South Africa is a developing country with a limited pool of professionally qualified individuals including engineers. The Human Sciences Research Council estimated that the demand for engineers increased by $40 \%$ in the years 1998-2003 (Ludski, 2001). According to van der Merwe and van der Merwe (2006) the demand for engineers has reached critical levels especially in the construction sector. In South Africa there are approximately 15000 engineers which is one-tenth of the international norm given the population of the country (van der Merwe \& van der Merwe, 2006).

This skills shortage can primarily be attributed to three main problems, firstly, too few students are entering the profession, secondly, emigration results in lost resources and thirdly, the retention of young graduate engineers beyond their socialization phase, is inadequate.

Over the past decade the number of students registering for undergraduate engineering degrees at South African universities has declined and the number of students achieving engineering degrees in recent years has also decreased (Steyn \& Daniels, 2003). The situation is further exacerbated by the decrease in the number of suitably qualified school-leavers with the required subjects (maths and science) to enter engineering degrees.

The engineering profession has also experienced rising levels of net migration of engineers and technicians over the last ten years (Steyn \& Daniels, 2003). In 1997, 95 immigrants in the category 'engineers and related technologists' arrived in South Africa and 372 left. In 1998, 77 immigrated into the country and 337 left (Forgey, Jeffery, Sidiropoulos, Smith, Corrigon, Mephuthing, Helman, Redpath \& Dimant, 2000).

Employees entering organizations for the first time need support in order to adjust to the working environment, yet, engineering managers are finding it increasingly difficult to motivate entrylevel engineers (Asai, 2004; Bigiliardi \& Petroni, 2005). This is attributed to factors like limited autonomy, inadequate feedback, low motivational levels, lack of a challenge and not enough involvement in the job itself (Hoyt \& Gerloff, 1999; Maki, 2001). In the organisation where the present study was conducted, concerted attempts have been made to attract and retain graduate engineers, particularly those who are from previously disadvantaged backgrounds. However, the organisation reports turnover figures for this particular group in excess of thirty percent per annum during their first five years of employment (personal communication, 1999).
In the context of the above problem the objectives of this study include:

1. Investigating whether entry expectations of graduate engineers in South Africa are congruent with early career experiences

2. Describing any incongruence between expectations and experiences.

3. Providing recommendations to individuals and organisations that will benefit from incongruence reduction.

Before describing this study in detail a review of the relevant literature about the early career stage is discussed. The early career stage, that typically encompasses the first few years of permanent employment, is a critical phase for both the individual and the organisation as first impressions are often lasting ones (Muchinsky, Kriek \& Schreuder, 2002; Schein, 1978). Perceptions formed by both parties contribute to attitude formation, which manifests itself in work behaviours. The belief on the part of the individual that they are making a meaningful contribution to the organisation early in their career leads to feelings of self worth and self respect which manifest in motivation and organisational commitment (Cohen, 1991). Research indicates that pre-entry socialization or anticipatory socialisation during recruitment and selection can contribute to the formation of realistic career expectations and the preliminary psychological contract between graduates and their employers (Scholarios, Lackyer \& Johnson, 2003). It is critical that experiences in the early career stage be understood and carefully managed both by individuals and their organisations. The quality of the management of this process can ultimately affect the levels of productivity of staff, commitment, level of job satisfaction, absenteeism, turnover rates as well as psychological well being.

For many years theorists have agreed on the common challenges faced by newcomers to organisations (Feldman, 1976; Schein, 1978; Wanous, 1980). These challenges include locating one's role in the organisation with respect to: the tasks assigned; other individuals in the organisation; and reconciling one's personal expectations of the workplace with the reality of work experiences, all elememts of the socialization process. As far back as 1976, Feldman argued that the first stage of socialistion is anticipating joining the organisation and begins with the formation of (un)realistic perceptions during recruitment. It concerns the congruence (matching) of the individual and the organisation. Feldman (1976) postulates that the more realistic the expectations and the higher the congruence, the easier the 
transition from outsider to insider will be. Yet, more recent research has suggested that the majority of graduates still have unrealistic expectations about their future careers (Scholarios, Lockyer \& Johnson, 2003). Incongruence results in reality shock. Reality shock occurs when a new employee's expectations, established prior to joining an organisation, differ significantly from what is expected (Dean, 1982). At least four major sources of expectations during pre-entry socialisation have been identified (Dean, 1982). These include societal stereotypes, childhood experiences, professional training and organisational entry experiences during recruitment and selection. An organisation has little or no influence over the first two sources and only occasionally over the third. However, job candidates have been found to actively form expectations during organisational entry which influence their decision to participate in the organisation (Dean, 1982). Research amongst graduate engineers indicates that reality shock has been evident for many years.

\section{Research amongst entry level engineers}

Research has been conducted around the attitudes and early experiences of young engineers in the United Kingdom with the emphasis on their work aspirations as they enter their first full time job after graduation (Keenan \& Newton, 1986). The results indicated that aspirations were largely unmet. In particular, issues pertaining to the work content rather than the work context were highlighted. Results revealed that the majority of individuals gave high priority to being able to exert influence over others, to work on their own initiative and to obtain esteem from others in their first job. Little interest was expressed in the management aspects of engineering work. Notable discrepancies existed between the desire to apply their knowledge and the opportunity to do so as well as the opportunity to make friends and to have a prestigious job (Keenan \& Newton, 1986). Similar results were reported in a recent internet survey that revealed that students expect high salaries, challenging work and that the employers' attitude towards personal time will be a determining factor in accepting employment offers (Costlow, 1999).

Bigiliardi and Petroni (2005) found that an inadequate understanding of engineers' expectations is strongly related to career dissatisfaction and organisational commitment. In support of earlier findings, their study suggests that factors such as responsibility, achievement, and a sense of contribution to the organisation as a whole, appear to be important factors of motivation for engineers. Challenge, creativity, flexibility and autonomy of the work itself are of paramount importance in generating job involvement and satisfaction amongst this occupational group (Asai, 2004). When incongruence exists between expectations and experiences, individuals engage in work adjustment (Dawis \& Lofquist, 1984).

The theory of work adjustment as advanced by Dawis and Lofquist (1984) is underpinned by the conceptualisation that work is an exchange between an individual (skills) and the work environment (tasks that require completion). Work adjustment is the process of achieving and maintaining correspondence between the individual and the environment in that they interact to the mutual satisfaction of both (Dawis \& Lofquist, 1984). This mutual satisfaction manifests itself in tenure whereby the individual continues to work in the environment. Tenure is an outcome of work adjustment and can be predicted from the correspondence of an individual's work personality with the work environment (Dawis \& Lofquist, 1984).

Hershenson (1996) expands the concept of work adjustment to accommodate three components: work role behaviour (involving acting appropriately to one's position in the work setting, which is primarily related to work personality in the person and the behavioural expectation of the work setting); task performance (involving the quality and quantity of one's work output, which is primarily related to work competencies in the individual and the skill requirements of the work setting); and, worker satisfaction (involving gratification from one's work which is primarily related to the work goals of the individual and the rewards or opportunities in the work setting). Central to the concept of work adjustment is the adaptability of the individual to new role demands (Schein, 1978; Super, 1992; Ashworth \& Saks, 1995). Schein (1978) postulates that a young adult is expected to adjust to multiple new roles relating to work, family and community life, often simultaneously. He suggests that psychological well being is informed by individual coping responses to multi-role adjustment (Schein, 1978) that includes dealing with reality shock, adjusting to work routines, becoming effective quickly, achieving acceptance at work, accepting responsibility, developing special skills, balancing individual needs with organisational demands and deciding whether or not to stay in the organisation (Schein, 1978).

As demonstrated, a link exists between the concepts organisational socialisation, reality shock and work adjustment. Organisational socialisation is a process through which individuals pass upon entering an organisation for the first time. During this process, the individual attempts to reconcile his/her various expectations with actual working experiences. If a significant difference is encountered and particularly if this difference proves to be a negative one for the individual, then reality shock is experienced.

The issues of individual expectations, organisational socialisation, reality shock and work adjustment provide the theoretical basis for this research. Research conducted in these fields specifically amongst engineers in America, the United Kingdom and South Africa (Breakell, 1991; Hershenson, 1996; Jiang \& Klein, 2003; Keenan \& Newton, 1986; Le Roux, Scheepers \& Lessing, 1997) has, for the most part, been quantitative in nature. That is, one or two particular constructs were selected and their relationship to career entry issues investigated (Breakell, 1991; Le Roux et al., 1997). The very foundations of work adjustment theory, however, are grounded in the fact that individual work personalities within a specific work environment result in unique work adjustments (Dawis \& Lofquist, 1984). For this reason, a case study was conducted and a qualitative approach followed to explore the relationship between individual expectations and experiences of work life, how the individual copes with any incongruence between these two constructs and what mechanisms could be employed by management, tertiary training institutions and individuals to manage these discrepancies.

\section{RESEARCH DESIGN}

\section{Research approach}

A qualitative methodology was employed in this study to understand the relationship between personal work expectations and experiences within a specific work context. The unit of analysis is the individual within the case. The bounded context in the current research is a large utility plant situated just outside Cape Town.

\section{Participants}

More specifically, the case can be defined as consisting of graduate engineers under the age of 30 with less than 5 years post graduate work experience, currently employed at the plant. There were 16 participants in the study, 15 males and one female. The selection of typical cases was informed by the fact that the information sought in this study is the responses and experiences of a sample of young engineers who typically represent a larger population. 


\section{Data collection}

In-depth qualitative research interviews were used to gather information. The interviews were semi-structured and an interview guide was utilised. The tape recording of interviews and subsequent transcripts constitute the material for further interpretation of meaning (Hummelvoll \& da Silva, 1998).

\section{Treatment of the data}

Qualitative research findings were inductively derived from this data (Maykut \& Morehouse, 1994). Strauss and Corbin's (1990) methods of qualitative data analysis were followed. Typed transcripts were analysed thematically. Repeated readings of transcripts enabled successive waves of data to be condensed into coherent clusters (Miles \& Huberman, 1994). The data was displayed visually and systematically in a clustered matrix (Miles \& Huberman, 1994). Reading across the rows provided the researchers with a brief profile of each participant and offered an initial test of the relationship between responses to different questions (Miles \& Huberman, 1994). Reading down the columns enabled the researchers to make comparisons between participants' responses. By analysing the information in the matrix, conceptual or theoretical coherence was established (Miles \& Huberman, 1994). With respect to establishing patterns, the researchers sought added evidence of the same theme from different participants whilst remaining open to disconfirming evidence, advice offered by Miles and Huberman (1994).

Clustering is used to better understand a phenomenon by grouping and then conceptualising objects that have similar patterns (Miles \& Huberman, 1996). It is the activity of conceptualising the grouped data that takes clustering one step further in analysis than simply noting patterns. In the present study, clusters were employed around events such as responses to work adjustment. In the present study, when themes or patterns are identified, they are based on the fact that a number of responses or behaviours occurred consistently. Therefore, in this sense, counting is employed in order to report clear patterns of response from participants (Miles \& Huberman, 1996). After clustering was employed to group variables together logically, analysis in the present study was taken one step further. Subsuming particulars into more general classes is a conceptual and theoretical activity (Miles \& Huberman, 1994). By employing this technique, fewer classes of variables are obtained as a precursor to attaining theoretical coherence. However, it should be noted that in the present study, definitive evidence was obtained in a minority of cases that disconfirmed general patterns of response. Such outlying evidence obviously could not be ignored and required independent analysis. Finally, the process of analysing and interpreting data in the present study progressed to interpreting the results in light of existing theory in the field. In addition to verifying much of the existing theory in the field, further insights are also offered by the research in the form of recommendations to parties engaged in early work adjustment.

\section{RESULTS}

The results of the thematic analysis confirm the first objective of the study that the expectations of graduate engineers in South Africa are incongruent with their early career experiences. The nature of the incongruence is described in the emergence of the following themes:

\section{Anticipation}

The findings clearly show that childhood experiences and societal stereotypes; university training; and organisational entry experiences established perceptions amongst participants that working as an engineer would provide an exciting, creative outlet for their desire to produce artifacts.
These factors contributed significantly to the formation of expectations on the part of participants around their careers. The participants believed that they would be well rewarded for their innovative contributions to a dynamic, developing field, which held desirable opportunities for their personal growth and career advancement.

\section{Reasons for vocational choice}

Childhood experiences of tinkering with mechanical and technical objects led participants to decide to become engineers in adulthood. The participants expected to be involved in the design and redesign of artefacts which would improve their functionality.

\section{University training}

A second variable that contributed to participants' work expectations was the nature of their university training. This finding strongly suggests that participants expected the nature of their work to be more creative and design focused, congruent with the principles learnt and projects completed when they were university students. At work, however, the participants spend the majority of their time maintaining existing machinery. The following comments capture this discord between expectations and reality, "...you use less than $5 \%$ of what you learn" and "You can write what you use from varsity on the back of a matchbox

\section{Recruitment}

The recruitment process served to reinforce the participants' inaccurate work expectations. There is no evidence that the organisation intentionally misled participants. Rather, participants reported projecting their work expectations onto the organisation in the absence of a realistic understanding of the day-to-day nature of their jobs.

\section{Induction}

The participants experienced their induction as inadequate and commented that it failed to alleviate the anxiety of starting to work for the first time in unfamiliar surroundings. "I was lost, completely lost, I thought, "how am I going to manage?" and "No one knew what I was supposed to be doing, they actually asked me what I was doing there and how long I was supposed to be there."

\section{REALITY SHOCK}

All the participants reported experiencing incongruence between expectations and experiences. Reality shock was experienced with respect to content of work, context of work and career mobility issues.

\section{Content of work}

The finding in this research is mainly one of participants discovering that their daily activities contain insufficient pure engineering tasks and an overabundance of routine paperwork. They experience high levels of reality shock with respect to the nature of their work and feel dissatisfied in that they perceive their talents to be under-utilised.

\section{Context of work}

A number of findings in this study reflect that reality shock was experienced by participants with respect to the context in which they perform their duties. Context refers to the environment in which work is conducted.

Interpersonal interaction. The finding in this study indicates that newcomers feel welcomed and comfortable in their interactions with the administrative and management employees in the organisation, but not at plant level with the artisans who deliberately attempt to humiliate young engineers. Evidently predecessors of this particular group of participants who 
displayed arrogance are responsible for this general attitude of artisans towards any new engineer. This antagonistic behaviour comes as a complete shock to the newcomers. It serves to undermine their confidence and inhibits their assimilation into the organisation.

\section{Supervision and mentoring}

The participants did not anticipate the large degree of autonomy granted them on entering the organisation. Opinions are equally divided over whether this autonomy is welcomed or not. The task that faces participants in this regard is how to become a good judge of one's own performance because unlike in the university environment regular feedback is not forthcoming. "I was on my own. Everything that I've learnt so far, I taught myself."

\section{Organisational climate}

A further finding in this study, with respect to the work context concerns the organisational culture or climate of the work environment. Participants frequently referred to the organisational climate of the organisation as exacerbating their sense of reality shock. "...to tell you the truth, when I started here it felt very limited, almost like you're in prison or something".

\section{ADJUSTMENT}

The thematic analysis revealed that as a group, the participants are still grappling with reality shock and employ various mechanisms to manage the negative consequences of this experience.

\section{Time}

This finding indicates that participants have to cope with a major adjustment in their perception of time. They experience the pace of daily activities and their own advancement as too slow. The participants in this study have all, but one, identified career goals for themselves linked to specified time frames but these might have to shift to accommodate the reality of the organisation's practices.

\section{Interpersonal interaction}

This finding indicates that participants have to adjust to interacting on a daily basis with a culturally diverse workforce. "Once you get to work with somebody else with a different background, its not a friction, but an uneasiness you have to get over". The participants report having to exercise humility in order to gain co-operation from their co-workers. They also modify their patterns of speech and vocabulary when interacting with different sub-groups of co-workers.

\section{DISCUSSION}

The results will be discussed in the same order they appear in the results section. The societal stereotypes of an engineer as a respected professional that is financially well-rewarded, contributed to the expectation that participants would be accorded this status, and prompted the choice of engineering as a future career.

The expectations of the participants in this study are underpinned by their work values. Greenhaus, Seidel, \& Marinus (1983) assume that an individual brings a relatively stable set of values to a job situation. The values underlying the expectations of the participants in this study include primarily, heuristics and creativity followed by achievement, prestige and material success. All of these have been identified as of importance to employees (Dawis \& Lofquist, 1984, Dose, 1997, Super, 1970). These particular values are personal as opposed to social and therefore less likely to be altered by organisational socialisation experiences (Dose, 1997). Work values are important because they involve the relationship between internal needs and the resulting motivation to act upon the environment to satisfy those needs (Landy \& Conte, 2004; Super, 1957, as cited in Yates, 1990).

The incongruence between expectations and experience can be understood if one considers earlier research into the degree of preparedness of university students for work, which produced similar findings (Purvis \& Panich, 1986; Schein ,1978). Purvis and Panich (1986) identify this same problem of underpreparedness in other professional training programmes such as accounting. Their recommendation is that students must be made to realise that they will not necessarily receive anticipated creative and independent assignments in the early stages of their early career (Purvis \& Panich, 1986). Their research shows that even when students receive a good technical grounding from their training institutions, they lack a coherent understanding of career requirements (Purvis \& Panich, 1986).

The lack of readiness on the part of the individual to make good choices and cope effectively with life stage developmental tasks is cited as an indicator of career immaturity (Scharf, 1992 as cited in Le Roux, Scheepers \& Lessing, 1997). Research by Le Roux et al. (1997) into the link between career maturity and accurate career expectations concludes that engineering students who were bursars did accurately anticipate their jobs because of repeated contact with the sponsoring organisation during their study years. This does not appear to be the case in the present study. Even those participants who had worked during their university vacations at the present organisation expected their full time responsibilities to be more challenging once they had graduated. Research suggests that realistic recruitment and selection processes could provide candidates with accurate information about the culture of the organization and job content (Scholarios, Lockyer \& Johnson, 2003).

Collectively, the findings of this study suggest that various expectations of the participants were to a greater or lesser extent disconfirmed by their early career experiences, specifically related to the content and context of work.

The finding of this study echoes findings in a similar study by Keenan and Newton (1986) within the engineering profession in the United Kingdom, where participants reported a notable discrepancy between their desire to apply their knowledge and the opportunities to do so.

The nature of work experience has important implications for the development of an identity for early career individuals. As one subject in the present study said: "An engineer is not what you do, it is who you are". The development of an identity is considered a critical task to be faced during socialisation as it provides the employee with a legitimate place in the organisation (Schein, 1978; Super, 1992; Wanous,1980).

The participants experiences with respect to the lack of autonomy and challenging work assignments in their early career stage mirror the results of Maki (2001) and Hoyt and Gerloff (1999) as discussed earlier. Further incongruence is experienced in relation to the context of work.

The participants received limited supervision and research suggests that supervisors may be the most potent source for facilitating newcomers' adjustment to and satisfaction with the organisation (Graen, 1976, as cited in Ostroff \& Kozlowski, 1992; Kaiser, 1997).

The finding in this study indicates that the mentoring process in this organisation is functioning to some extent but needs improvement. Ambitious young individuals whose career goals include upward mobility, strongly seek out 
opportunities for development from their mentors as they view them as a major reference group (Whitely \& Coetsier, 1993). This is exactly the situation with the participants in this study who consciously select mentors themselves in some cases and all commit to the process. Commitment from the individual, the mentor and company management is critical to the success of the mentoring process (Colwell, 1998; Maloney, 1999). Mentors should act not only as coaches who seek to develop skills in their protégés, but also as protectors of newcomers from political forces within the organisation and fulfill a psychosocial function (Aryee \& Wyatt, 1996; Schoenfeld \& Magnan, 1994; Whitely \& Coetsier, 1993).

Organisational climate is a surface level indicator of the broader concept of organisational culture and is an individual construct that reflects an orientation based on personal values (Vianen \& Prins, 1997 as cited in Shadur, 1999). The finding in this regard suggests that significant adaptation on the part of individuals is required in order to adjust to the bureaucratic structures that permeate the organisation. Difficulties arise when ambitious, energetic individuals have to internalise this culture and adapt their work personalities to contain their impatience. Participants in this study report feeling stifled by the environment in which they work and sometimes blame superiors for deliberately slowing their progress. In order to avoid the possibility that different values are operating at different hierarchical levels, it is essential that management diagnose and assess the culture/climate that is operating lower in the organisation and explicitly monitor the induction and early socialisation process (Altmann, 2000; Alvesson, 2002; Schein, 1978, Schein, 1992; Vecchia, 1995).

Shadur (1999) suggests that a key factor contributing to individual involvement in an organisation is the organisational climate which can either facilitate or impair employee involvement. These perceptions reflect the way in which an employee describes the workplace (Altmann, 2000) which in this study is reported by participants to be rigid and slow moving.

Participants experienced work processes to be too slow and opportunities for advancement too distant. Little research is available on the studies of time perception by individuals in a work setting. One contribution in this field comes from Seijts (1998) who explored the relationship between time perspective and personal motivation to achieve goals. People who are more oriented towards the future place a great value on doing future oriented tasks (Seijts, 1998). This has implications for the participants who are frustrated with the pace of the organization and their prospective career development path.

Participants reported not being adequately prepared to work effectively in a culturally diverse workforce. In South Africa, this issue add a further dimension to work adjustment in general because the former dispensation imposed severe restrictions on inter-cultural interaction. Increasingly, employees are working with people who have different values and perceptions shaped by diverse cultural backgrounds. Differences between groups can result in the erection of barriers to their integration (Berger, 1996). Problems of differences in language and the ability to communicate with other groups contribute to inter group antagonisms (Berger, 1996).

The final objective of the research was to be able to develop recommendations on how the incongruence could be managed more effectively.The recommendations offered in this section include suggestions for facilitating the organisational entry of newcomers in order to avoid discrepancies between expectations and experiences.

\section{RECOMMENDATIONS}

\section{Recommendation for the organization}

These recommendations are offered sequentially, following the typical order of activities performed when a new employee is sought and employed by an organisation.

\section{Recruitment}

Advertisements intended to attract suitable candidates to the organisation should be carefully worded to reflect the true nature of daily tasks. If the primary tasks envisaged for the new employee are maintenance tasks, this should be articulated clearly in job advertisements. During the interviews conducted with applicants, realistic job previews should be presented. These previews should emphasise the nature of the duties to be performed and a clear message should be sent to the applicant around the volume of paperwork required. Applicants should be informed about lengthy procedures and the general pace of activities. If possible, shortlist candidates should be escorted on a brief tour of the utility plant in order to familiarise them with their future workplace.

\section{Aligning individual and organizational work values}

Attaining a value match between the individual and the organization remains a critical component of the selection process. A comprehensive profile of the individual's work values compared with the organisation's values may reveal potential congruence between the two. Strong evidence from this research indicates that the good financial rewards on offer from the organisation are not the most valued aspect of work for young engineers, who primarily seek challenging tasks.

\section{Induction}

Immediate supervisors should be prepared better for the arrival of a new member of their department. Designated work space should be allocated in advance of the new employee arriving and a meaningful task identified for completion by the newcomer. Ideally, a peer of the new employee, who already knows the organisation, should be assigned to assist the newcomer during the first few days.

\section{Psychological Contract}

A member of the organisation should devote time with each individual newcomer in order to compile a psychological contract. This should be a written document which articulates expectations from both parties. A discussion around the contents of this contract offers an opportunity for unrealistic expectations to be highlighted and possibly reformed early in the entry period.

\section{Training}

The content of training courses offered by the organisation is regarded as being of a very high standard. The only areas of difficulty with respect to training are that new employees shoulder sole responsibility for deciding which courses to attend and sometimes in obtaining permission to attend them. It is suggested that during their first year of employment, the training schedule be more structured and directive. Thereafter, the current system of self-initiated training could be employed.

\section{Mentoring}

Mentoring is perceived as necessary and valuable to young engineers. However the role of mentor should not be imposed upon individuals in the organisation. Rather, mentors should be volunteers who are given specific training for the role.

The above recommendations are offered to the organisation in the light of the reported difficulties that engineers express experiencing upon organisational entry. They are intended to create more realistic expectations among applicants and 
facilitate their assimilation into the organisation. However, the full responsibility for preparing individuals for the world of work does not rest exclusively with organisations. Universities also have a role to play.

\section{Recommendations to tertiary institutions}

Universities have to strike a fine balance in their curricula in order to meet the dictates of international academic excellence and the needs of industry. At present the emphasis is clearly upon the former with courses that teach design and pure engineering principles. Whilst these should remain the essential core focus, two further aspects leave students significantly under-prepared for the realities of working in large organisations.

\section{Practical Skills}

It is unlikely that universities will shift their entire focus to practical training. The Universities of Technology fulfill this aspect more than adequately but engineering diplomas from these institutions do not carry the desired status of university degrees. Whilst resources are admittedly limited, the academic year is short $(+32$ weeks $)$ and a supplementary two week practical course could significantly improve the ability of students to apply their theoretical knowledge. Whether conducted on the university campus or at co-operative organisations, this course should include knowledge of tools and machinery commonly encountered in an engineering environment. Furthermore, projects intended to test the knowledge of students with regard to design principles should include an element of functionality. Students should produce artifacts that not only look aesthetically pleasing, but actually work. Extensions of due dates for projects should not be granted lightly in order to encourage students to learn to meet deadlines.

\section{Interpersonal skills}

Graduate engineers report one of their work adjustment issues as the need to cultivate the ability to communicate with other people in the organisation who represent diverse cultural backgrounds. The current six month communication module included in engineering degree courses emphasises written communication. Whilst written skills are important, an effort should be made to include interpersonal skills such as conflict resolution, interaction in meetings and sensitivity training. Students should be encouraged to work in culturally diverse groups which reflect the real work situation. Responsibility for preparing oneself for the realities of work life also rests upon the individual.

\section{Recommendations to Student Engineers}

These recommendations to student engineers are offered by the participants interviewed in this study. They can be categorised into three distinct responsibilities that students should recognise as their own, including the formation of expectations, activities whilst at university, and attitude.

\section{Expectations}

Students should, as far as possible, develop realistic expectations about their future work life. They should take note of their duties during vacation work and not assume that 'things will be different' when they eventually take up full time positions of employment. Graduates should not anticipate extensive design work and should ask incisive questions during interviews around the nature of daily activities. They should also try and develop realistic perceptions of time with respect to advancement. A five year period in a large organisation before promotion is more realistic than one or two years.

\section{Student Life}

During their full-time student phase, individuals should interact as much as possible with other students from diverse cultural backgrounds. They should not isolate themselves from communicating with others. Furthermore, they should try and exercise self-discipline with respect to meeting assignment deadlines and coping with routine in anticipation of work place demands. By scanning newspaper employment advertisements, they could gain an insight into realistic market-related salaries for graduate engineers.

\section{Attitude}

Finally, when joining an organisation for the first time, the primary advice offered by current employees is to exercise humility. By acknowledging that they still have much to learn from individuals with less education but more experience than themselves, interpersonal interactions are significantly eased. Humility needs to be balanced with a proactive approach to seeking information. Students are advised to ask questions and take responsibility for initiating their own development.

This case study explored the relationship between the work expectations and work experiences of a sample of engineers during their early career stage. It explored individual work adjustment responses to the incongruence encountered

In the current South African climate of limited professional human resources, greater understanding of individual experiences is essential, if highly qualified graduates are to be retained both in organisations and the country. Critical to the retention of these individuals is their psychological well-being at work. The results of this study indicate that significant incongruence is experienced at the individual level between work expectations and reality. Thus psychological well-being is negatively affected, which has potentially adverse consequences for the organisation and the individual.

The results of the case study suggest that revision of current practices is required by individuals, universities and organisations, in order to facilitate the attainment of congruence between the expectations and experiences of early career individuals. Increased congruence will result in improved psychological well-being which will in turn benefit individuals and organisations alike.

\section{REFERENCES}

Altmann, R. (2000). Understand the organisational climate Canadian Manager, 25 (2). Retrieved March 22, 2001, from EBSCO database (Academic Search Elite) on the World Wide Web: http://www.ebsco.com

Alvesson, M. (2002). Understanding organizational culture. London: Sage

Aryee, S. \& Wyatt, T. (1996). Early career outcomes of graduate employees: The effect of mentoring and ingratiation. Journal of Management Studies, 33 (1). Retrieved February 21, 2001 from EBSCO database (Business Source Premier) on the World Wide Web: http://www.ebsco.com.

Asai, C. (2004). Interrelationship among and determinants of professional commitment, organizational commitment, and job motivation of contingency engineers. Japanese Journal of Experimental Social Psychology, 43, (2), 174- 184.

Ashworth, B.E. \& Saks, A.M. (1995) Work-role transitions: A longitudinal examination of the Nicholson model. Journal of Occupational and Organisational Psychology, 68, 157-175.

Berger, M. (1996). Cross cultural team building: guidelines for more effective communication and negotiation. London: McGrawHill

Bigiliardi, B. \& Petroni, A. (2005). Status, role and satisfaction among development engineers. European Journal of Innovation Management, 8, (4), 453-470.

Breakell, L.D. (1991). Newcomers in organisational entry coping with early job experience. Journal of Industrial Psychology, 17 (3), 13-18. 
Cohen, A. (1991). Career stage as a moderator of the relationships between organisational commitment and its outcomes: A meta-analysis. Journal of Occupational Psychology, 64, 253-268.

Colwell, S. (1998). Mentoring, socialisation and the mentor/protégé relationship. Teaching in Higher Education, 3 (3). Retrieved February 21, 2001, from EBSCO database (Academic Search Elite) on the World Wide Web: http://www.ebsco.com

Costlow, T. (1999) Tomorrow's engineers speak up. Electronic Engineering Times, 1076. Retrieved April 10, 2000, from EBSCO database (Academic Search Elite) on the World Wide Web: http://www.ebsco.com

Dawis, R.V. \& Lofquist, L.H. (1984). A psychological theory of work adjustment. Minneapolis:University of Minnesota Press

Dean, R.A. (1982) Reality shock: The link between socialisation and organisational commitment. Journal of Management Development, 2 (3). 55-65.

Dose, J.J. (1997). Work values: An integrative framework and illustrative application to organisational socialisation. Journal of Occupational and Organisational Psychology, 70, 219-240.

Feldman, D.C.(Ed). (1976). Work Careers: a developmental perspective. San Francisco: Jossey-Bass

Forgey, H., Jeffery, A., Sidiropoulos, E., Smith, C., Corrigon, T., Mephuthing, T., Helman, A., Redpath, J. \& Dimant, T. (2000). South Africa Survey 1999/2000 millenium edition. Braamfontein: Institute of Race Relations. 247- 318

Greenhaus, J.H., Seidel, C. \& Marinus, M. (1983). The impact of expectations and values on job attitudes. Journal of Organisational Behaviour and Human Performance, 31, $294-417$.

Hershenson, D.B. (1996). Work adjustment: a neglected area in career counselling, Journal of Counselling and Development, 74 (5), 442. Retrieved April 10, 2000, from EBSCO database (Academic Search Elite) on the World Wide Web: http://www.ebsco.com.

Hoyt, J. \& Gerloff, E.A. (1999). Organizational environment, challenging economic conditions and the effective supervisors of technical personnel. A management challenge. The Journal of High Technology Management Research, 10, (2), 225-293.

Hummelvoll, J.K. \& da Silva, A.B. (1998). The use of the qualitative research interview to uncover the essence of community psychiatric nursing. Journal of Holistic Nursing, 16 (4). Retrieved June 19, 2000, from EBSCO database (Academic Search Elite) on the World Wide Web: http://www.ebsco.com.

Jiang, J. \& Klein, G. (2002). A discrepancy model of information system personnel turnover. Journal of Management Information Systems, 19 (2), 249-272

Kaiser, T.L. (1997). Supervisory relationships: Exploring the human element. Pacific Grove: Brooks Cole Publishing Company.

Keenan, A. \& Newton, T.J. (1986). Work aspirations and experiences of young graduate engineers. Journal of Management Studies, 23 (12), 224-237.

Landy, F.J. \& Conte, J. M. (2004). Work in the 21st Century: an introduction to Industrial and Organizational Psychology. Boston: McGraw-Hill

Le Roux, H., Scheepers, J.M., \& Lessing, B.C. (1997). The relationship between career maturity, career expectations and perceptions of job and organisational knowledge of engineering bursars. Journal of Industrial Psychology, 23 (2),31-38.

Ludski, H. (2001, March 25). Skills logjam a thing of the past. Sunday Times Business Times, 3, 1.
Maloney, L. (1999). The mentoring art. Design News, 54 (13) Retrieved February 21, 2001, from EBSCO database (Masterfile) on the World Wide Web: http://www.ebsco.com.

Maki, D.M. (2001). Work motivation for software engineers. Journal of Humanities and Social Sciences, 61 (12A).

Maykut, P. \& Morehouse, R. (1994). Beginning Qualitative Research. London: The Falmer Press.

Miles, M.B. \& Huberman, A.M. (1994) Qualitative Data Analysis (2nd ed). California: Sage

Muchinsky, P., Kriek. H. \& Schreuder, D.(2002). Personnel Psychology. (2 $2^{\text {nd }}$ ed). Cape Town: Oxford University Press.

Ostroff, C. \& Kozlowski, S.W.J. (1992). Organisational socialisation as a learning process: the role of information acquisition. Personnel Psychology, 45, 849-874

Purvis, S.E.C. \& Panich, R.L. (1986). Improving upon the firstyear retention rate of entry-level professionals. CPA Journal, 56 (12), 101

Schein, E.H. (1978). Career dynamics: Matching individual and organisational needs. (1 $1^{\text {st }}$ ed.). Phillipines: Addison-Wesley

Schein, E.H. (1992). Organizational culture and leadership. San Francisco: Jossey-Bass

Schoenfeld, A.C. \& Magnan, R. (1994). Mentor in a manual. (2nd ed). Arizona:Magno Publishers Inc.

Scholarios, D., Lockyer, C. \& Johnson, H. (2003). Anticipatory socialization: the effect of recruitment and selection experiences on career expectations. Career Development International, 8 (4), 182-197

Schreuder, A.M.G. \& Theron, A.C. (1997). Careers: An organisational perspective. Cape Town: Juta \& Co.

Seijts, G.H. (1998). The importance of future time perspective. Journal of Psychology Interdisciplinary and Applied, 132 (2). Retrieved September 5, 2000, from EBSCO database (Academic Search Elite) on the World Wide Web: http://www.ebsco.com.

Shadur, F. (1999). The relationship between organisational climate and employee perceptions of involvement. Group and Organisation Management, 24, 4. Retrieved March 22, 2001, from EBSCO database (Academic Search Elite) on the World Wide Web: http://www.ebsco.com.

Strauss, A.L. \& Corbin, J. (1990). Basics of qualitative research: grounded theory procedures and techniques. Newbury Park, California: Sage

Steyn, G. \& Daniels, R.C. (2003). Human Resources Development Review 2003: Education, Employment and Skills in South Africa, Cape Town: HSRC Press and East Lansing: Michigan State University Press

Super, D.E. (1970). Work values inventory. Chicago: Riverside

Super, D.E. (1992). Toward a comprehensive theory of career development in career development: Theory and Practice. Eds D.H. Montross and C.J. Shinkman. Illinois: Charles C. Thomas Publishers

Van der Merwe, P. \& van der Merwe, C. (2006). Engineers have the world at their feet. Grad X. 18-20

Vecchia, R.P. (1995). Organisational behaviour. (3rd ed). Fort Worth, TX: Dryden Press, Harcourt Brace College Publishers

Wanous, J.P. (1980). Organisational entry: Recruitment, selection and socialisation of newcomers. Philippines: Addison-Wesley

Whitely, W.T. \& Coetsier, P. (1993). The relationship of career mentoring to early career outcomes. Organisation Studies, 14 (3), 419-441

Yates, L.V. (1990). A note about values assessment of occupational and career counselling. Journal of Measurement and Evaluation in Counselling and Development, 23 (1), 54. Retrieved April 10, 2000, from EBSCO database (Academic Search Elite) on the World Wide Web: http://www.ebsco.com. 